\title{
Metabolic Syndrome in Hypothyroid Patients
}

\author{
R Haque ${ }^{1}$, S Ferdousi ${ }^{2}$, SS Ferdousi $^{3}$, W Rahman ${ }^{5}$, MN Uddin $^{4}$, MM Hoque $^{5}$ \\ ${ }^{1}$ Dept of Biochemistry, Sir Salimullah Medical College, Dhaka \\ ${ }^{2}$ Dept of Biochemistry, Dhaka Medical College, Dhaka \\ ${ }^{3}$ Dept of Gynaecology and Obstretrics, Sir Salimullah Medical College,Dhaka \\ ${ }^{4}$ Dept of Biochemistry, National Institute of Cardiovascular Diseases, Dhaka \\ ${ }^{5}$ Dept of Biochemistry, Bangabandhu Sheikh Mujib Medical University(BSMMU), Dhaka
}

\begin{abstract}
Thyroid functions affect metabolic syndrome (MetS) parameters including blood pressure, fasting plasma glucose, serum triglycerides and HDL-Cholesterol. But the relationship between MetS and thyroid functions is yet to be identified clearly. Metabolic syndrome is a state in which most features of hypothyroidism can be seen. The aim of the present study was to investigate the frequency of MetS in hypothyroid patients. Thirty one patients with overt hypothyroidism, 32 patients with subclinical hypothyroidism $(\mathrm{SCH})$ and 58 euthyroid controls were enrolled in this study. NCEP-ATP III criteria was used to diagnose metabolic syndrome. Majority of the participants were in the age group of 30-40 years. Body mass index and waist circumference, blood pressure, fasting plasma glucose and serum triglycerides were found to be higher in hypothyroid patients compared to that of euthyroid controls $(p<0.001)$. On the other hand serum HDL-C was found to be significantly lower in hypothyroid patients compared to that of euthyroid controls $(\mathrm{p}<0.001)$. Prevalence of MetS was $82.5 \%$ in the hypothyroid group and $27.6 \%$ in eythyroid controls $(\mathrm{p}<0.001)$. No significant difference was found between SCH $(81.3 \%)$ and overt hypothyroid $(86.7 \%)$ groups in respect to prevalence of MetS $(p<0.05)$. The findings of the study suggest a need to investigate the presence of hypothyroidism during the management of MetS patients.
\end{abstract}

Key Words: Overt hypothyroidism, Subclinical hypothyroidism, Metabolic syndrome, Lipid profile

\section{Introduction}

Metabolic syndrome, previously known as Syndrome- $X$, constitutes a cluster of abnormalities including abdominal obesity, insulin resistance, hypertension, hypertriglyceridemia and decreased high density lipoprotein cholesterol ${ }^{1}$. Reaven ${ }^{2}$ noted that several risk factors like dyslipidemia, hypertension and hyperglycemia commonly cluster together which he called Syndrome $X$ and recognized it as a multiplex of risk factors for cardiovascular diseases. Syndrome $X$ has now been re-designated as metabolic syndrome (MetS) after WHO named it so in 1999. WHO included several parameters as the diagnostic criteria for metabolic syndrome such as presence of diabetes mellitus, hypertension, hypertriglyceridemia and

Bangladesh J Med Biochem 2014; 7(2): 57-61 low serum HDL-cholesterol and high BMI3. The National Cholesterol Education Program's Adult Treatment Panel 111 (NCEP- ATP 1ll) report identified the metabolic syndrome as a multiplex of risk factors for cardiovascular diseases that deserve more clinical attention ${ }^{4}$. Modified NCEPATP 111 for MetS includes raised fasting plasma glucose, hypertension, hypertriglyceridemia, low serum HDL cholesterol and increased waist circumference ${ }^{1}$.

Hypothyroidism is caused by suboptimal concentration of circulating thyroid hormones. The prevalence of hypothyroidism has been reported to vary in different countries. The worldwide prevalence of hypothyroidism is 
Metabolic Syndrome in Hypothyroid Patients

1:100, but it may increases to $5: 100$ if patients of subclinical hypothyroidism are included ${ }^{5}$. Hypothyroidism is identified as the most common thyroid disorder in Bangladesh in different studies done by 'Endocrine Clinic' of Bangabandhu Sheikh Mujib Medical University ${ }^{6}$. It is estimated that, about $5 \%$ of our population are suffering from hypothyroidism. The frequency of hypothyroidism, both overt and subclinical is quite high in our country ${ }^{7}$.

Thyroid hormones play an essential role in regulating energy balance, metabolism of glucose and lipids and thus affect MetS parameters including HDL-C, triglyceride (TG), blood pressure and plasma glucose ${ }^{8}$. Hypothyroidism is associated with obesity, dyslipidemia and increased risk of atherogenic cardiovascular diseases ${ }^{9}$. Substantial evidences support that overt hypothyroidism potentiates several of the traditional risk factors of cardiovascular diseases. Subclinical hypothyroidism is a prevalent condition among adult population which is frequently overlooked. About one sixth of the metabolic syndrome patients attending the outpatient Department of a training and research hospital in Istambul, Turkey were found to have subclinical hypothyroidism ${ }^{10}$. It is estimated that $20-25 \%$ of South Asian have metabolic syndrome and many more are prone to develop it ${ }^{11}$. There is inadequate and scanty data in the context of our settings regarding the relationship between thyroid status and metabolic syndrome. So the study was undertaken to investigate the frequency of metabolic syndrome in hypothyroid patients, both overt and subclinical.

\section{Material and Methods}

This cross sectional study was carried out from July 2011 to May 2011 in the Department of Biochemistry, Bangabandhu Sheikh Mujib Medical University, Dhaka, Bangladesh. Study protocol was approved by local ethical committee and all participants gave written informed consent prior to entry in the study. One hundred and twenty one subjects were selected from Centre for Nuclear Medicine and Ultrasound, Dhaka Medical College. Newly diagnosed hypothyroid patients according to selection criteria were selected. Patients with serum TSH level $>5.0$
$\mathrm{mU} / \mathrm{L}$ and normal $\mathrm{FT}_{4}$ level $(9.5-25 \mathrm{pmol} / \mathrm{L})$ were taken as subclinical hypothyroidism, TSH $>10.0 \mathrm{mU} / \mathrm{L}$ and $\mathrm{FT}_{4}<9.5 \mathrm{pmol} / \mathrm{L}$ were taken as overt hypothyroidism and TSH level (0.5$5.0 \mathrm{mU} / \mathrm{L})$ and FT4 level $(9.5-25.0 \mathrm{pmol} / \mathrm{L})$ were taken as euthyroid group. Patients with known diabetes or other endocrine disorders, having pregnancy, renal diseases, liver diseases, old cases of hypothyroid, history of thyroidectomy or receiving steroid, lipid lowering agent or oral contraceptives were excluded from the study. Baseline demographic data were collected. Sitting Blood pressure was measured at least after 10 minutes of rest by standard procedure. A second measurement was made after at least 3 minutes. The mean of two measurements was taken for systolic and diastolic blood pressure ${ }^{10}$. Height in $\mathrm{cm}$ and weight in $\mathrm{kg}$ were measured with light clothing and without shoes. Waist circumference in $\mathrm{cm}$ was measured at the plane in the midpoint between the lower costal margin and highest point of iliac crest using a plastic measuring tape. Blood samples were collected following 12 hours of fasting and were centrifuged (2500rpm) after clot have been formed and retracted. From the separated serum fasting glucose, serum triglycerides, serum HDL cholesterol were measured by enzymatic method. MetS was diagnosed according to modified NCEP-ATP III criteria \{presence of $\geq 3$ of the following: 1 . Waist circumference $>90 \mathrm{~cm}$ in male, $>80 \mathrm{~cm}$ in female. 2. SBP: $\geq 130 \mathrm{~mm}$ of $\mathrm{Hg}$ and/or DBP: $\geq 85$ $\mathrm{mm}$ of $\mathrm{Hg}$ (or use of antihypertensive medication). 3. TG: $\geq 150 \mathrm{mg} / \mathrm{dl}$. 4. HDL-C > $40 \mathrm{mg} / \mathrm{dl}$ in male, $>50 \mathrm{mg}$ in female. 5. Fasting glucose $\geq 6.1 \mathrm{mmol} / \mathrm{L}\}$.

The results were expressed as mean $\pm \mathrm{SD}$ and proportions. CI (95\%) was calculated for proportions. Comparisons were done by unpaired t-test. The $p$ value of $<0.05$ was considered statistically significant.

\section{Result}

A total of 121 subjects were enrolled for the study of which 105 were females and 16 were males. They were classified into euthyroid, subclinical hypothyroid and overt hypothyroid according to their serum TSH and $\mathrm{FT}_{4}$ status. Of the total subjects, 58 were euthyroid and 63 were 
hypothyroid. Among the hypothyroid subjects, 32 were in the subclinical hypothyroid and 31 were in the overt hypothyroid groups. Majority of the study subjects in euthyroid and hypothyroid groups were in the age group of 30-40 years. Age distribution and clinical characteristics of the groups are depicted in the Table I and Table II respectively. Groups were similar in terms of age and sex distribution. Table III showed the mean values of BMI, waist circumference, systolic and diastolic blood pressure, fasting plasma glucose, triglycerides which were higher in hypothyroid subjects compared to euthyroid controls $(p<0.001)$. Serum HDL cholesterol levels were found to be significanty lower in the hypothyroid group compared to that of euthyroid controls $(\mathrm{p}<0.001)$.

The prevalence of MetS in hypothyroid subjects was $82.5 \%$ compared to that euthyroid $(27.5 \%)$ which was statistically significant $(\mathrm{p}<0.001)$. Among overt hypothyroid subjects, frequency of MetS was a bit higher (Table IV and Table V).

Table I: Distribution of study subjects according to age and thyroid status $(\mathrm{n}=121)$

\begin{tabular}{llll}
\hline $\begin{array}{l}\text { Age } \\
\text { (yrs) }\end{array}$ & Euthyroid & $\begin{array}{l}\text { Subclinical } \\
\text { hypothyroid (SCH) }\end{array}$ & $\begin{array}{l}\text { Overt } \\
\text { Hypothyroid }\end{array}$ \\
\hline $18-30$ & 20 & 10 & 11 \\
$30-40$ & 22 & 12 & 16 \\
$40-50$ & 16 & 10 & 04 \\
Total & $\mathbf{5 8}$ & $\mathbf{3 2}$ & $\mathbf{3 1}$ \\
\hline
\end{tabular}

Table II: Anthropometric measurements, biochemical parameters and blood pressure of study subjects (clinical characteristics).

\begin{tabular}{|c|c|c|c|c|c|c|}
\hline \multirow[t]{2}{*}{ Parameters } & \multicolumn{2}{|c|}{$\begin{array}{l}\text { Euthyroid } \\
(\mathrm{n}=58)\end{array}$} & \multicolumn{2}{|l|}{$\begin{array}{l}\mathrm{SCH} \\
(\mathrm{n}=32)\end{array}$} & \multicolumn{2}{|c|}{$\begin{array}{l}\text { 0vert } \\
\text { Hypothyroidn=31) }\end{array}$} \\
\hline & Mean $\pm S D$ & Range & Mean \pm SD & Range & Mean \pm SD & Range \\
\hline BMI & $24.2 \pm 2.5$ & $20.0-32.0$ & $27.9 \pm 2.9$ & $23.3-34.6$ & $28.2 \pm 2.9$ & $22.2-34.9$ \\
\hline $\mathrm{WC}(\mathrm{cm})$ & $83.8 \pm 4.9$ & $73-96$ & $92 \pm 8.4$ & $75-106$ & $92.1 \pm 7.9$ & $78-105$ \\
\hline $\mathrm{FPG}(\mathrm{mmol} / \mathrm{L})$ & $4.9 \pm 0.3$ & $4.0-5.8$ & $5.8 \pm 0.8$ & $4.3-8.0$ & $5.7 \pm 0.6$ & $4.9-8.0$ \\
\hline $\mathrm{TG}(\mathrm{mg} / \mathrm{dl})$ & $137 \pm 31$ & $57-201$ & $159 \pm 42$ & $74-260$ & $183 \pm 45$ & $98-275$ \\
\hline $\mathrm{HDL}(\mathrm{mg} / \mathrm{dl})$ & $44.7 \pm 5.5$ & $27-62$ & $40.2 \pm 6.3$ & $31-56$ & $39 \pm 9.5$ & $27-59$ \\
\hline SBP(mm Hg) & $116.3 \pm 9.9$ & $80-130$ & $125.3 \pm 11.4$ & $100-140$ & $125 \pm 12.4$ & $95-150$ \\
\hline $\mathrm{DBP}(\mathrm{mm} \mathrm{Hg})$ & $76.3 \pm 6.4$ & $60-90$ & $82.5 \pm 8.0$ & $60-100$ & $84.3 \pm 7.3$ & $65-100$ \\
\hline
\end{tabular}

* WC: Waist circumference
Table 1ll: Comparison of BMI, WC, biochemical parameters and blood pressure between euthyroid and hypothyroid subjects.

\begin{tabular}{llll}
\hline Variable & $\begin{array}{l}\text { Euthyroid } \\
(\mathbf{n = 5 8})\end{array}$ & $\begin{array}{l}\text { Hypothyroid } \\
(\mathbf{n = 6 3 )}\end{array}$ & p-value \\
\hline & mean \pm SD & mean \pm SD & \\
BMI & $24.2 \pm 2.5$ & $28.0 \pm 2.9$ & $<0.001$ \\
Waist circumference(cm) & $83.8 \pm 4.9$ & $92.2 \pm 7.7$ & $<0.001$ \\
FPG(mmol/L) & $4.9 \pm 0.3$ & $5.7 \pm 0.7$ & $<0.001$ \\
Insulin $(\mu \mathrm{U} / \mathrm{ml})$ & $7.6 \pm 3.7$ & $11.5 \pm 6.7$ & $<0.001$ \\
TG(mg/dl) & $137 \pm 31.2$ & $171.0 \pm 45.4$ & $<0.001$ \\
HDL(mg/dl) & $44.7 \pm 5.5$ & $40.1 \pm 8.0$ & $<0.001$ \\
SBP(mmHg) & $116.4 \pm 9.9$ & $125.2 \pm 11.8$ & $<0.001$ \\
DBP(mmHg) & $76.4 \pm 6 . .5$ & $83.4 \pm 7.7$ & $<0.001$ \\
& & & \\
\hline
\end{tabular}

Table IV: Prevalence of metabolic syndrome among the study subjects $(n=121)$

\begin{tabular}{lclll}
\hline Group & Frequency of MetS & $\begin{array}{l}\text { Prevalence } \\
\text { Point estimate }\end{array}$ & 95\% CI & p-value \\
\hline & 16 & $27.5 \%$ & $16.0-39.0$ & $<0.001$ \\
$\begin{array}{l}\text { Euthyroid } \\
(\mathrm{n}=58)\end{array}$ & 52 & $82.5 \%$ & $73.2-91.8$ & \\
$\begin{array}{l}\text { Hypothyroid } \\
(\mathrm{n}=63)\end{array}$ & 52 & & & \\
\hline
\end{tabular}

Table V: Prevalence of metabolic syndrome among different types of hypothyroid study subjects.

\begin{tabular}{llllr}
\hline Group & $\begin{array}{l}\text { Frequency of } \\
\text { MetS }\end{array}$ & $\begin{array}{l}\text { Prevalence } \\
\text { Point estimate }\end{array}$ & $\mathbf{9 5 \%}$ CI & p-value \\
\hline $\begin{array}{l}\text { SCH } \\
(\mathrm{n}=32)\end{array}$ & 26 & $81.2 \% \%$ & $67.7-94.7$ & $\supset 0.05$ \\
$\begin{array}{l}\text { Overt } \\
\text { hypothyroid } \\
(\mathrm{n}=31)\end{array}$ & 26 & $83.8 \%$ & $70.9-96.7$ & \\
\hline
\end{tabular}

\section{Discussion}

High prevalence of MetS is a global phenomenon. Hypothyroidism and metabolic syndrome are recognized risk factors for atherosclerotic cardiovascular disease. The aim of the present study was to find out frequency of MetS in hypothyroidism.

Majority of the study subjects were female which indicates the preponderance of hypothyroidism among the females compared to males. Luboshitzky et $\mathrm{al}^{12}$ found that BMI were similar in $\mathrm{SCH}$ and euthyroid controls but waist circumference was greater in their study subjects. 
This study revealed that both BMI and waist circumference were greater in SCH group compared to that of euthyroid controls. Maratou et $\mathrm{al}^{13}$ and Ganidagly et $\mathrm{al}^{14}$ found significantly higher FPG levels in hypothyroid patients which is in agreement with the findings of this study. Luboshitzky et al. ${ }^{12}$ found that $34.1 \%$ of the study subjects with subclinical hypothyroidism were hypertensive. In our study about half of the individual in both the subclinical and overt hypothyroid groups had raised systolic and diastolic blood pressure and only one fifth euthyroid subjects had shown to have raised blood pressure. Our study also revealed significant difference in serum TG level between euthyroid and hypothyroid subjects. Thyroid hormone influences the transport of TG rich lipoproteins through its effect on lipoprotein lipase. Different studies also showed elevated levels of TG for subclinical hypothyroid subjects ${ }^{12,15}$. But a study showed a higher TG level even in subjects with a TSH level in the upper normal range ${ }^{16}$.

This study used modified NCEP-ATP III criteria, which include lower values as cut-off points for waist circumference compared to that of NCEPATP III and higher values for HDL cholesterol compared to WHO criteria. Most of the study subjects in hypothyroid group (56 out of 63) showed higher waist circumference as well as lower HDL cholesterol level.

The mean fasting level of HDL cholesterol was found to be significantly lower in hypothyroid group than that of euthyroid controls. This finding agree with the finding of Althas et al. ${ }^{17}$, but many researchers found no difference in HDL cholesterol concentration both in hypothyroid and euthyroid group 15,18 .

The study revealed that $27 \%$ of the biochemically euthyroid subjects were positive for MetS according to the modified NCEP-ATP III criteria. This is in agreement with other studies done at home and abroad. Rahim et al. ${ }^{19}$ in a study done in a rural community of Bangladesh, found that $20.7 \%$ of the population had metabolic syndrome according to the modified NCEP-ATP III. Among the hypothyroid subjects $82.5 \%$ fulfilled the criteria for metabolic syndrome in this study. Frequency of metabolic syndrome was similar in
$\mathrm{SCH}(81.2 \%)$ and overt hypothyroidism $(83.8 \%)$. Ganidagly et al. ${ }^{14}$, in Turkey, found that $44 \%$ of the hypothyroid, $35 \%$ of the $\mathrm{SCH}$ had metabolic syndrome according the NCEPATP III criteria.

This study found that prevalence of MetS is quite high in overt as well as SCH. So both groups of people need to be screened for MetS and cardiometabolic risk factors. On the other hand, people with MetS need to be screened for presence of hypothyroidism. This clinical awareness will substantially help to give adequate attention to MetS, hypothyroidism and cardio-metabolic risk factors in an attempt to reduce the morbidity and mortality out of MetS, hypothyroidism and cardiovascular diseases.

\section{References}

1. Dhanraj E, Bhansali A, Jaggi S, Dutta P, Jain S, Tiwari P. Prevalence and predictors of metabolic syndrome in nonobese Asian Indians with newly detected type 2 diabetes mellitus. J Ind Med Assoc 2008; 106: 366-72.

2. Reaven GM. Role of insulin resistance in human disease. Diabetes 1988; 37: 1595-1607.

3. World Health Organization: Definition, diagnosis and classification of diabetes mellitus and its complications: report of a WHO consultation. Part 1: diagnosis and classification of diabetes mellitus. Available at http://whqlibdoc.who.int/hq/ 1999/who_NCD_NCS_99.2pdf

4. Grundy SM, Brewer B, Cleeman JI, Smith SC, Lenfant C. 'Definition of Metabolic syndrome', Proceedings of the National Heart, Lung and Blood Institute/American Heart Association Conference on Scientific Issues related to Definition. Circulation 2004; 109: 433-38.

5. Strachan MWJ and Walker BR. Endocrine diseases in NA Boon, NR Colledge and BR Walker(eds), Davidson's Principle and practice of Medicine, 20th ed, Churchill Livingstone, New York, 2006: 739-804.

6. Alam MN, Haq SA, Ansari MAG, Karim MA, Das KK, Baral PK . Spectrum of thyroid disorder in IPGMR, Dhaka, Bangladesh. Bangladesh J Med 1995; 6: 53-8. 
7. Selim S. Hypothyroidism. 2011. The daily Sun, 24 March: p-2

8. Kumar HK, Yadav RK, Prajapati J, Reddy CV, Raghunath M, Modi KD. Association between thyroid hormone, insulin resistance and metabolic syndrome. Saudi Med J 2009; 30: 907-11.

9. Cappola AR and Ladenson PW. Hypothyroidism and atherosclerosis. J Clin Endocrinol Metab 2004; 88: $2438-44$.

10. Uzunlulu M, Yorulmaz E and Oguz A. Prevalence of subclinical hypothyroidism in patients with metabolic syndrome. Endocrinol J 2007; 54: 71-6.

11. Eapen D, Kalra GL, Merchant N, Khan BV. Metabolic syndrome and cardiovascular disease in South Asians. Vasc Health Risk Manag, 2009; 5:731-43, viewed 18 April 2010, $<$ http: / / w w w n c bi.nlm.nih.gov/ pubmed/19756165>

12. Luboshitzky R, Ishay A and Herer P. Metabolic syndrome and insulin resistance in women with subclinical hypothyroidism. The Endocrinologist 2010; 20: 29-32.

13. Maratou E, Aviv A, Herer P, Lavie L. Risk factors for cardiovascular disease in women with subclinical hypothyroidism. Thyroid 2002; 12: 421-25.
R Haque, S Ferdousi, SS Ferdousi et al

14. Ganidagli S, Erdogan M,Kosenti A, Kulaksizoglu M, Solmaz S, Sokmen, Canataroglu A. frequency of metabolic syndrome in hypothyroid patients. Endocrine Abstracts 2009; 20: 97, http://www. endocrine-abstracts.org/ea/0020/ea 0020p97.htm

15. Turhan S, Sezer S, Erden G, Guctekin A et al. Plasma homocysteine concentrations and serum lipid profile as atherosclerotic risk factors in subclinical hypothyroidism. Ann Saudi Med 2008; 28: 96-101.

16. Ruhla S, Weickert MO, Arafat AM, Osterhoff M. A high normal TSH is associated with metabolic syndrome. Clin Endocrinol 2009; 72: 696-701.

17. Althus BU,Staub JJ, Ryff-De Leche A, Oberhansli A, Stahelin HB. LDH/HDL changes in subclinical hypothyroidism:possible risk factors for coronary heart diseases. Clin Endocrinol 1988; 28: 157-63.

18. Hueston WJ and pearson WS. Subclinical hypothyroidism and risk of hypercholesterolemia. Ann Fam Med 2004; 2: 421-426

19. Rahim MA, Khan AKA, Sayeed MA, Akhter B, Nahar Q, Ali SMK, Hussain A. Metabolic syndrome in rural Bangladesh: Comparison of newly proposed IDF, Modified ATP III and WHO criteria and their agreements. Diabetes and Metabolic Syndrome: Clin Res Rev 2007; 1: 251-57. 